\title{
An experimental study of by-products of successive discrimination learning in the pigeon
}

\author{
JOHN C. DAMRON and KENNETH R. BURSTEIN \\ Simon Fraser University, Burnaby, British Columbia V5A 1S6, Canada
}

\begin{abstract}
Four experimental groups and a control group, of five pigeons each, were trained to successively discriminate a vertical amber line from one oriented either 30 or $60 \mathrm{deg}$ to the right. Depending on group, pecks were intermittently reinforced by either 2.5 or 5.0 sec access to the food hopper. During discrimination, the subjects were provided a second response key, a peck upon which provided a 5-sec time-out (TO) from either the positive or the negative stimulus. Frequency of response on both the TO key and the discrimination key was monitored throughout. After the discrimination training, all subjects were given a postdiscrimination generalization test. Although peak shift was not obtained, the results support the hypothesis that byproducts of successive discrimination learning are functions of magnitude of $\mathrm{S}+$ reinforcement and degree of $\mathrm{S}+/ \mathrm{S}-$ separation. It was concluded that the results are consistent with a conflict theory of by-products of discrimination learning.
\end{abstract}

In successive discrimination training, a subject is alternately presented two stimuli: $\mathrm{S}+$, which is correlated with reinforcement, and $\mathrm{S}-$, which is correlated with nonreinforcement or extinction. Three well-known "by-products"' usually accompany the development of differential stimulus control in this procedure. These are peak shift, positive behavioral contrast, and $\mathrm{S}-$ aversiveness. $^{1}$

According to Terrace, each of these by-products disappears with extended discrimination training (Terrace, 1966, 1971), and none develops if the discrimination is acquired without "errors," that is, responses to $\mathrm{S}$ - (Terrace, 1966).

According to Terrace $(1971,1972)$, by-products of discrimination learning originate in the occurrence of frustration-producing responses in the $\mathrm{S}$ - condition. However, this view has not held up well to experimental test (see, e.g., Rilling, 1977, pp. 469-470). Moreover, Terrace's theory cannot readily account for by-products occurring in the context of aversive conditioning procedures wherein $\mathrm{S}-$ is correlated with the nonaversive condition (Hearst, 1969, p. 36).

In noting the foregoing problems, Hearst (1969) has questioned the parsimony of the $\mathbf{S}$ - aversiveness concept and, in the same stroke, made the case for a more general gradient-interaction model of discrimination learning such as the one developed by Spence (1937). Such a model is not without convincing empirical support (see, e.g., Hearst, 1968, 1969).

\footnotetext{
This study was a portion of a thesis submitted by the first author in partial fulfillment of the requirements for the degree of Master of Arts in psychology at Simon Fraser University. Requests for reprints should be addressed to John C. Damron, Department of Psychology, Simon Fraser University, Burnaby, British Columbia V5A 1S6, Canada.
}

However, it is not clear how gradient-interaction theory accounts for positive behavioral contrast and $\mathrm{S}$ - aversiveness. Since the empirical reality of these phenomena has been demonstrated (Reynolds, 1961; Rilling, Askew, Ahlskog, \& Kramer, 1969; Terrace, 1971), it would seem to be incumbent upon proponents of gradient-interaction theory to show how the theory might be expanded to account for the foregoing byproducts.

In this spirit, the purpose of this study was to investigate aspects of a general gradient-interaction theory, wherein it is proposed that $\mathrm{S}-$ aversiveness and related by-products of discrimination learning are functions of dispositional conflict at $\mathrm{S}$ - between inhibitory and generalized excitatory tendencies accruing to that stimulus as a result of discrimination training.

The experiment below specifically examines two conflict-affecting variables: degree of $\mathrm{S}+/ \mathrm{S}-$ separation and magnitude of $\mathrm{S}+$ reinforcement. Through their respective effects on level of generalized response strength at $\mathrm{S}$ - and overall elevation of the prediscrimination generalization gradient (cf. Tarpy, 1975 , p. 152 , pp. 185-187), these factors affect the absolute level of response to undergo inhibition during training and, therefore, the level of conflict inherent in the procedure. Following from this, we hypothesize that conflict, and therefore the magnitude of the various by-products, will increase as $\mathrm{S}+$ reinforcement rises and $\mathrm{S}+/ \mathrm{S}-$ separation diminishes.

\section{METHOD}

\footnotetext{
Subjects

The subjects were 25 male and female White King pigeons reduced to and maintained at $75 \%$ of their ad-lib weights.
} 


\begin{abstract}
Apparatus
The experiment was conducted in a Grason-Stadler (E1100PE) three-key operant conditioning station. White noise was piped into the station from a Grason-Stadler (E829E) noise generator. The center key was illuminated by a Grason-Stadler (20378) stimulus projector equipped to project a 1-in.-long, 1/16-in.-wide amber line in 12 possible orientations against a black background. During the discrimination phase of the experiment, the right response key was operative, illuminated by a white light, and programmed, if pecked, to produce a 5-sec TO from prevailing center-key stimulation. It was covered and inoperative during all other phases. The left key was covered and inoperative throughout the experiment. Variable-interval (VI) reinforcement was programmed by a Grason-Stadler (1079) celluloid tape reader. After initial keypeck training, center-key stimulation was programmed in blocks of 1 min duration and separated by a 5 -sec interstimulus interval, during which the experimental chamber was entirely dark.
\end{abstract}

\section{Procedure}

Phase 1. Subjects were randomly assigned to four groups consisting of different combinations of $\mathrm{S}+/ \mathrm{S}-$ differences $(0$ and $30 \mathrm{deg}$ right or 0 and $60 \mathrm{deg}$ right) and reinforcement magnitude (2.5- or 5.0-sec hopper time). Thus, groups were designated, respectively: $30-2.5,60-2.5,30-5.0$, and 60-5.0. Five subjects were also assigned to a control group, designated " $C$," which was identical to the 60-5.0 experimental group, except that pecks on the right key eliminated only its own light for $5 \mathrm{sec}$. Responses on this key did not produce TOs from the discriminative stimuli. Subjects were then magazine trained and shaped to peck the center key, upon which an amber line in the vertical orientation was projected. Following keypeck training, responses were reinforced for one session on each mult VI 15-sec/VI 15-sec and mult VI 30-sec/ VI 30-sec schedules of reinforcement. Thereafter, all responses in the baseline phase were reinforced on a mult VI $60-\mathrm{sec} / \mathrm{VI} 60-\mathrm{sec}$ schedule of reinforcement. Subjects were trained on this schedule for 15 consecutive sessions, in order to obtain a stable measure of baseline response rate. Baseline was determined by calculating mean rate of response over the last five sessions.

Phase 2. The TO key was uncovered and rendered operative, and $\mathrm{S}+$ was irregularly alternated with an $\mathrm{S}-$ orientation of either 30 or $60 \mathrm{deg}$ right. The duration of stimulus presentation was $60 \mathrm{sec}$. Presentations were separated by a 5 -sec interstimulus interval, during which the experimental chamber was entirely dark. Responses in the $\mathrm{S}+$ condition continued to be reinforced on a VI 60 -sec schedule of reinforcement; all responses in $S-$ went unreinforced. Subjects were trained on the discrimination procedure until response rate in the $S$ - condition had fallen to $10 \%$ or lower of response rate in $\mathrm{S}+$. Contrast effects were determined by calculating mean $\mathrm{S}+$ response rate over all discrimination sessions to criterion for each subject and then subtracting baseline estimate (Phase 1) from this value. The difference was then transformed into percentage increase.

Phase 3. The TO key was rendered inoperative, and a postdiscrimination generalization test, consisting of 12 cycles of nine randomly sequenced line orientations, was administered to all subjects. The orientations were 0 deg (vertical) and 15, 30, 45, and $75 \mathrm{deg}$ left and right. During the test, stimulus duration was reduced from 60 to $30 \mathrm{sec}$. All test responses went unreinforced. Response rate in the presence of all stimulus values was monitored.

\section{RESULTS}

Peak shift was not obtained (see Figure 1). However, substantial gradient shifts were obtained. "Gradient shift" refers to the reallocation of generalization test responses from symmetrical to nonsymmetrical distribution around $\mathrm{S}+$ as a function of discrimination training. The relative magnitudes of
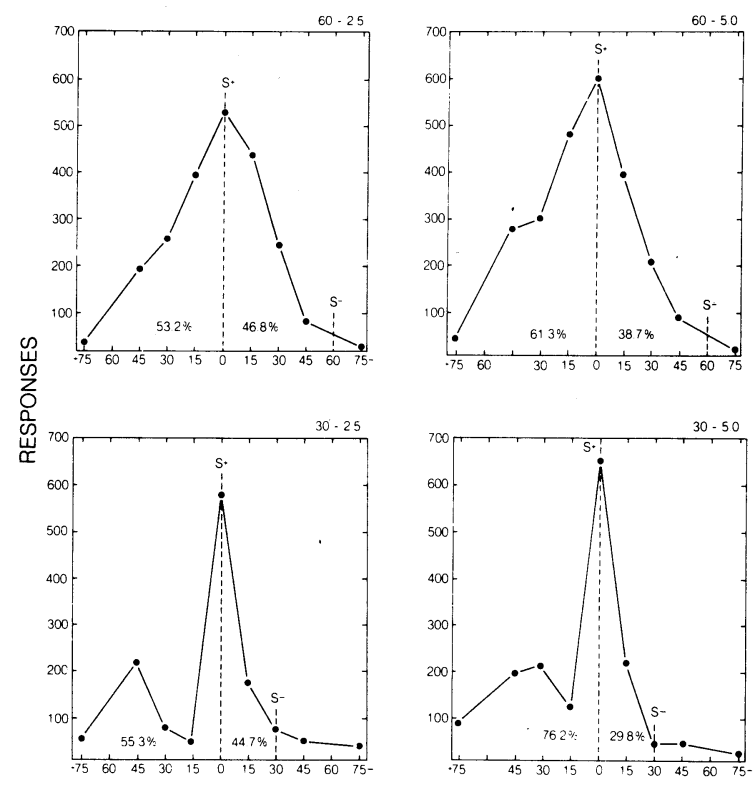

DEGREES OF LINE ORIENTATION

Figure 1. Postdiscrimination generalization gradients for four groups as a function of $S+$ reinforcement magnitude and $S+/ S-$ separation.

gradient shift were: Group 60-2.5, 2.2\%; Group 302.5, 5.3\%; Group 60-5.0, 11.3\%; and Group 30-5.0, $20.2 \%$. In all cases, gradient shift was to the left, that is, in a direction opposite to S-. After arcsin transformation, an analysis of variance revealed that those groups differing only in magnitude of reinforcement in S+ differed significantly in degree of gradient shift $[F(1,16)=21.0, p<.001]$. Those groups differing only in degree of $\mathrm{S}+/ \mathrm{S}-$ separation were also significantly different $[F(1,16)=5.69$, $\mathrm{p}<.05]$. An analysis of reinforcement magnitude by stimulus difference revealed no statistically significant differences.

Behavioral contrast effects were obtained in all groups and were as follows: Group 60-2.5, 27.0\%; Group 30-2.5, 42.0\%; Group 60-5.0, 54.1\%; and Group 30-5.0, 101.6\%. An analysis of variance revealed that those groups differing only in magnitude of reinforcement differed significantly in extent of behavioral contrast effect $[F(1,16)=10.1, p<.01]$. Those groups differing only in degree of $\mathrm{S}+/ \mathrm{S}-$ separation were also significantly different $[F(1,16)=$ $5.25, \mathrm{p}<.05]$. An analysis of reinforcement magnitude by stimulus difference disclosed no statistically significant difference.

As operationally defined in the introduction, substantial S- aversiveness effects were obtained in all groups and were, in terms of mean number of TOs from S- per discrimination session: Group 60-2.5, 29.3; Group 30-2.5, 48.1; Group 60-5.0, 69.3; and Group 30-5.0, 86.2. An analysis of variance disclosed that those groups differing only in magnitude of rein- 
forcement differed significantly in number of TOs from $\mathrm{S}-[\mathrm{F}(1,16)=100.83, \mathrm{p}<.001]$. Those groups differing only in degree of $\mathrm{S}+/ \mathrm{S}-$ separation were also found to be significantly different $[F(1,16)=21.62$, $\mathrm{p}<.001$ ]. Reinforcement magnitude by stimulus difference was found to be statistically nonsignificant. TOs from $\mathrm{S}+$ were, in every group, negligible (i.e., approaching zero). Hence, no analysis was required.

A $t$ test was done between mean TOs in Group 605.0 and a control group identical to 60-5.0 except that no contingency existed between pecks on the second key and TOs from the discriminative stimuli (Group C). Mean sessional TOs for the former group were 69.3, and mean number of pecks on the "second key" for the latter group was 2.1 (range $=2.6-3.2$ ). The comparison between the groups was significant beyond .001 .

\section{DISCUSSION}

With the exception of peak shift, the results are consistent with the hypothesis advanced in the introduction. With respect to the failure to obtain peak shift, it should be noted that peak shift was originally obtained along the wavelength continuum (Hanson, 1959). Subsequent research in which peak shift has been demonstrated has, by and large, employed wavelength. Although Guttman (1965) has argued that peak shift may be restricted solely to the wavelength continuum, some researchers (e.g., Bloomfield, 1967) have obtained peak shift along the line orientation dimension. However, several others have failed to do so (e.g., Guttman, 1965; Hearst, 1968, 1969).

If peak shift can be generally regarded as a special case of deviation of postdiscrimination generalization responses from systematically graded to essentially nongraded distributions, then a sort of "peak shift" was obtained herein. Gradients 30-5.0 and 30-2.5 both evidenced substantial deviation from gradedness in the 30- and 45-deg-left $(+)$ sections of their respective generalization gradients (see Figure 1). This tendency was not conspicuous in the gradients of Groups 60-5.0 and 60-2.5. However, it is conceivable that an $\mathrm{S}+/ \mathrm{S}-$ separation of $45 \mathrm{deg}$ would have resulted in a nongraded generalization gradient and, perhaps, a peak shift, as conventionally defined.

The idea that $\mathrm{S}-$ aversiveness originates in conflict set up by interacting excitatory and inhibitory generalization gradients differs from Terrace's (1972) theory in that S- aversiveness is presumed to result from development of inhibition, and thus opposing response tendencies, at $\mathrm{S}-$. Terrace has taken a different position, namely, that inhibition at $\mathrm{S}-$ results from $\mathrm{S}-$ aversiveness. As noted in the introduction, it is difficult for such a theory to account for by-products of discrimination learning obtained within the context of aversive conditioning procedures (e.g., Cowan, 1968; Siegel, 1967). Since interacting excitatory and inhibitory gradients are present in discriminative aversive conditioning procedures (Desiderato, 1969), the presence of by-products is readily explicable in terms of the present conflict theory.

The present analysis may bear on an often cited weakness in the Spence-Hull theory of discrimination learning (Hull, 1952; Spence, 1937). That theory predicts a decrement in response strength in the S+ condition as a consequence of discrimination training. What is usually observed, however, is an increment in response strength (i.e., behavioral contrast) (Dunham, 1968; Reynolds, 1961).

The present model accounts for behavioral contrast in terms of conflict and $\mathrm{S}-$ aversiveness resulting from the interaction of excitatory and inhibitory generalization gradients. Although the particular feature of conflict and S- aversiveness that is responsible for contrast is not well known, we suggest that it may be diffuse arousal (cf. Duffy, 1941, 1957). The type of relationship imagined here among conflict, aversive stimulation, and arousal has been skillfully noted elsewhere (cf. Berlyne, 1960, p. 10, pp. 173-178) and will therefore not be elaborated here. We simply propose that conflict and S- aversiveness elevate arousal that in turn elevates response frequencies.

In the context of the conflict model proposed herein, we surmise that the Spence-Hull theory of discrimination learning neglects to take into account the transitory emotional and behavioral ramifications of conflict set up by gradient interaction and, as a result, fails to predict contrast.

As Purtle (1973, pp. 408-409) noted in his review of the peak shift literature, Hearst and his colleagues (e.g., Farthing \& Hearst, 1968; Hearst, 1968, 1969) have made the case for retention of Spence-Hull theory while also emphasizing the importance of other factors in the stimulus control of behavior. Other writers (e.g., Spiker, 1970) have favored formal extension of Spence-Hull theory. Insofar as the present work focuses on a factor new to conventional Spence-Hull analyses but nevertheless explicable within the general framework of that theory, it is clearly in the spirit of both of these views.

\section{REFERENCES}

Berlyne, D. E. Conflict, arousal and curiosity. New York: McGraw-Hill, 1960.

BLoomfie LD, T. M. A peak shift on a line-tilt continuum. Journal of the Experimental Analysis of Behavior, 1967, 10, 361-366.

Cow An, R. E. Contrast and peak shift following classical conditioning. Unpublished master's thesis, University of Missouri, 1968.

Desiderato, O. Excitation and inhibition: Stimulus control of avoidance behavior. Journal of Comparative and Physiological Psychology, 1969, 68, 611-616.

DufFY, E. An explanation of emotional phenomena without use of the concept of emotion. Journal of General Psychology, 1941, 25, 283-293.

Duffy, E. The psychological significance of the concept of "arousal" or "activation." Psychological Review, 1957, 64, 265-275.

Dunham, P. J. Contrasted conditions of reinforcement: A selective critique. Psychological Bulletin, 1968, 69, 295-315.

Farthing, G. W., \& Hearst, E. Generalization gradients of inhibition after different amounts of training. Journal of the Experimental Analysis of Behavior, 1968, 11, 743-752.

GutTman, N. Effects of discrimination formation on generalization measured from a positive-rate baseline. In D. Mostofsky (Ed.), Stimulus generalization. Palo Alto: Stanford University Press, 1965.

Hanson, H. M. Effects of discrimination training on stimulus generalization. Journal of Experimental Psychology, 1959, 58, 321-334.

He arst, E. Discrimination learning as the summation of excitation and inhibition. Science, 1968, 162, 1303-1306.

HE ARST, E. Excitation, inhibition and discrimination learning. In N. J. Mackintosh \& W. K. Honig (Eds.), Fundamental issues in associative learning. Halifax: Dalhousie University Press, 1969.

Hull, C. L. A behavior system. New Haven: Yale University Press, 1952.

Purtle, R. B. Peak shift: A review. Psychological Bulletin, $1973,80,408-421$.

REYNOLDS, G. S. Behavioral contrast. Journal of the Experimental Analysis of Behavior, 1961, 4, 57-71.

Rilling, M. Stimulus control and inhibitory processes. In W. K. Honig \& J. E. R. Staddon (Eds.), Handbook of operant behavior. Englewood Cliffs, N.J: Prentice-Hall, 1977.

Rilling, M., Askew, H. R., Ahlskog, J. E., \& Kramer, T. J. Aversive properties of the negative stimulus in a successive discrimination. Journal of the Experimental Analysis of Behavior, 1969, 12, 917-932.

SiEgEL, A. Stimulus generalization of a classically conditioned 
response along a temporal dimension. Journal of Comparative and Physiological Psychology, 1967, 64, 461-466.

SPENCE, K. The differential response in animals to stimuli varying within a single dimension. Psychological Review, 1937, 44, 430-444.

SpIKer, C. C. An extension of Hull-Spence discrimination learning theory. Psychological Review, 1970, 77, 496-515.

TARPY, R. M. Basic principles of learning. Palo Alto: Calif: Scott, Foresman, 1975.

Terrace, H. S. Behavioral contrast and peak shift. Journal of the Experimental Analysis of Behavior, 1966, 9, 313-317.

Terrace, H. S. Escape from S-. Learning and Motivation, 1971, 2, 148-163.

TERraCE, H. S. By-products of discrimination learning. In G. Bower \& J. Spence (Eds.), The psychology of learning and motivation (Vol. 5). New York: Academic Press, 1972.

\section{NOTE}

1. Peak shift is defined as the deplacement of the postdiscrimination generalization gradient maxima away from $\mathrm{S}+$ in a direction opposite to $\mathrm{S}-$. By positive behavioral contrast, we mean an increment in response frequency in the $\mathbf{S}+$ condition as a function of nonreinforcement or diminished reinforcement in the S- condition. S- aversiveness refers to the tendency of the stimulus correlated with nonreinforcement during discrimination training to become "noxious" by that training. Operationally, this amounts to the tendency of the experimental subject to escape from Sby emitting a response that produces a brief TO from S-.

(Received for publication July 28,1980 .) 